\title{
CONTRIBUIÇÕES DA TEORIA CRÍTICA PARA UMA REFLEXÃO SOBRE AS RELAÇÕES ASSIMÉTRICAS NO INTERIOR DO GRUPO LGBTI
}

\author{
Arísio Antonio Fonseca Junior ${ }^{1}$ \\ Emely Braga ${ }^{2}$
}

\begin{abstract}
Resumo: O presente ensaio objetiva realizar um exercício avaliativo das relações internas ao grupo LGBTI, considerado o diagnóstico de que há no interior desse grupo assimetrias de participação e poder entre as pessoas. Essa circunstância confere a alguns componentes do grupo preponderância no estabelecimento de pautas a serem postas externamente ao movimento com a consequente invisibilização de demandas minoritárias. Para tentar solucionar essa situação, apresentamos um diálogo entre as propostas teóricas de Nancy Fraser e Rainer Forst como forma de proporcionar aos membros do grupo LGBTI um ambiente democrático participativo e deliberativo em igualdade de apresentação das pretensões.
\end{abstract}

Palavras-chave: Paridade participativa. Direito à justificação. Igualdade. Movimento LGBTI. Teoria crítica.

\section{INTRODUÇÃO}

A teoria social crítica, pode-se falar no singular sobre esses modelos de análise social produzidos por uma diversidade de autoras e autores, tem como características mais ou menos peculiares das pesquisas, não só a realização de um diagnóstico das condições de vida de uma dada sociedade no tempo e no espaço, mas também a elaboração de uma certa normatividade aplicável às relações sociais daquela sociedade. Tentar observar o

\footnotetext{
${ }^{1}$ Mestre em Direito pela Universidade Federal de Ouro Preto. Bacharel em Direito pela Universidade Federal de Juiz de Fora. Advogado.

2 Mestra em Direito pela Universidade Federal de Ouro Preto. Bacharela em Direito pelo Centro Universitário Newton Paiva.
}

Vol. 03, N. 10, Abr. - Jun., 2020 - http://periodicoscientificos.ufmt.br/ojs/index.php/rebeh/index 
grupo $\mathrm{LGBTI}^{3}$ pela perspectiva da teoria social crítica, tendo como pano de fundo a inclusão desses sujeitos nas linguagens política e jurídica, implica realizar, em primeiro lugar, um exame, ainda que breve, das relações travadas entre as pessoas LGBTI, para, em seguida, propor a utilização de parâmetros normativos que esperamos sejam aptos a orientar as disputas internas pelo status de igualdade das demandas do grupo.

O presente ensaio objetiva, assim, utilizar um diálogo entre duas perspectivas teóricas críticas da sociedade para examinar as relações internas do grupo LGBTI. Enquanto boa parte dos estudos toma como objeto a relação entre o grupo LGBTI e a sociedade, pretendemos articular alguns aspectos das teorias de justiça de Nancy Fraser (paridade participativa) e de Rainer Forst (direito à justificação) como possíveis arranjos normativos para regular as disputas entre as pessoas dentro do próprio grupo LGBTI.

Iniciamos pela compreensão de que, a partir do olhar de um observador externo, o grupo LGBTI e suas demandas parecem apresentar um caráter homogêneo em relação às suas pautas políticas, sociais e jurídicas. Contudo, ao se voltar o olhar para as relações internas do grupo, estabelecidas entre as pessoas gays, lésbicas, bissexuais, travestis, transexuais, transgêneros, assexuais, intersexo etc., é possível que algumas assimetrias de poder e de status sejam percebidas, refletindo em posições de dominação e opressão quanto às demandas do grupo em direção à sociedade.

A abordagem é teórica e se sustenta em uma atividade imaginativa acerca das dimensões de hierarquização entre as pessoas LGBTI no âmbito do grupo social. Para tanto, produções acadêmicas e jornalísticas são consideradas para a elaboração do ensaio, sendo referenciadas como exemplificativas da concorrência existente dentro do grupo LGBTI.

Por fim, apresentamos considerações sobre a possibilidade do estabelecimento de um ambiente democrático deliberativo dentro do grupo LGBTI, com a participação paritária entre as pessoas LGBTI na definição justificada de demandas que congreguem em algum consenso os desejos e as necessidades delas. Esse seria um caminho para

\footnotetext{
${ }^{3}$ A opção por apresentar a sigla como LGBTI decore da proposta desta Revista para o presente dossiê, que utilizou a mesma sigla.
}

Vol. 03, N. 10, Abr. - Jun., 2020 - http://periodicoscientificos.ufmt.br/ojs/index.php/rebeh/index 
enfrentar de modo mais coeso e robusto as disputas existentes no âmbito do Estado contra posições majoritárias decorrentes da heterocisnormatividade.

\section{Disputas internas no grupo LGBTI}

A relação entre o grupo LGBTI e a heterocisnormatividade majoritária na sociedade brasileira, a qual informa, exemplificativamente, as estruturas políticas, sociais, jurídicas, educacionais e éticas, é assunto das mais diversas áreas de produção do conhecimento $^{4}$. Apenas nesta Revista, é possível observar a variedade de perspectivas teóricas e disciplinares por meio das quais aquela relação é analisada. Todavia, o exame das relações internas ao grupo LGBTI não é rotineiro nos trabalhos que tratam dos encontros e desencontros, das hierarquias e da competição por determinar as pautas políticas e sociais do movimento LGBTI.

Não é nossa pretensão minudenciar e exemplificar as disputas internas ao grupo LGBTI. Para isso, seria necessário um trabalho empírico, que foge ao âmbito deste ensaio. Não obstante, a história do movimento LGBTI permite a observação de que, intragrupo, as pessoas concorrem pelo direito de ser parte visível do movimento e de influenciar as demandas apresentadas para fora do grupo.

Uma mirada em textos que abordam a história do grupo LGBTI é suficiente para perceber como a mudança na "sopa de letrinhas" é significativa da situação que aqui mencionamos. Conforme observação de Francisca de Paula de Oliveira (2013, p. 31), o movimento teve algumas siglas para se identificar: em um primeiro momento, tratou-se de aglutinar as demandas de gays e lésbicas, razão porque o movimento homossexual estabeleceu-se como Movimento de Gays e Lésbicas (MGL); com a emergência

\footnotetext{
4 Conforme apontam Lauren Berlant e Michael Warner (2002, p. 230), "por heteronormatividade entendemos aquelas instituições, estruturas de compreensão e orientações práticas que fazem não só que a heterossexualidade pareça coerente - quer dizer, organizada como sexualidade - mas também que seja privilegiada". E, ainda segundo esses autores, não se deve confundir heteronormatividade com heterossexualidade, uma vez que aquele termo não encontra paralelo em seu oposto como ocorre com o último, ou seja, não há um conceito de homonormatividade, como há o de homossexualidade. Isso porque "a homossexualidade não pode possuir jamais a correção tácita e invisível para a formação social que possui a heterossexualidade" (BERLANT; WARNER, 2002, p. 230). Assim, a heterocisnormatividade se apresenta, se se pode dizer que ela se apresenta, nas sutis e despercebidas normas sociais, políticas e jurídicas em que os pares hetero/homo e cis/trans acabam tomando como padrão os primeiros termos das oposições.
}

Vol. 03, N. 10, Abr. - Jun., 2020 - http://periodicoscientificos.ufmt.br/ojs/index.php/rebeh/index 
organização das travestis e das pessoas trans na década de 1990, o grupo passa a se chamar Movimento de Gays, Lésbicas e Travestis (OLIVEIRA, 2013, p. 31; CARVALHO; CARRARA, 2013, p. 326 e 330; IRINEU, 2016, p. 93); nos anos 2000, outros atores e atoras também se apresentam para compor o grupo e demandar sua visibilidade, acrescentando o $\mathrm{B}$, de bissexuais, à sigla, que passa a ser movimento GLBTT (gays, lésbicas, bissexuais, travestis e transgêneros); até que, em 2008, na I Conferência Nacional GLBT, estabeleceu-se a ordem atualmente utilizada como LGBT (OLIVEIRA, 2013, p. 31).

Compreendido como um grupo que agrega demandas por inclusão social, política e jurídica, é possível considerar o grupo LGBTI como um movimento social, seguindo o conceito elaborado por Maria da Glória Gohn (2000, p. 13). Interessada na definição de movimento social, a autora aponta critérios que podem ser aplicados ao grupo LGBTI, constituindo-o como agente relevante na arena política brasileira em busca da aplicação da igualdade, da liberdade e da dignidade para gays, lésbicas, bissexuais, transgêneros etc. Segundo esse conceito, o movimento LGBTI possui suas ações coletivas que politizam demandas e desenvolvem lutas baseadas na solidariedade do grupo com base em valores compartilhados. Como movimento social, por um lado, o grupo LGBTI apresenta-se ao Estado e à sociedade como portador de interesses e demandas bastante harmônicos. Contudo, na perspectiva interna do movimento LGBTI, há ocorrência de disputas decorrentes das mais variadas causas.

Assim, utilizamos a expressão grupo LGBTI para nos referirmos ao conjunto de pessoas composto por gays, lésbicas, bissexuais, travestis, transexuais, transgênero, intersexo, queer, assexuais, etc., sendo certo que a expressão equivale, para fins deste ensaio, a movimento LGBTI. Entendemos que grupo denomina um conjunto de pessoas que estão conectadas de alguma forma, sem, contudo, apresentar homogeneidade em sua composição ou em suas reivindicações. Neste caso, grupo LGBTI é usado como um conjunto de pessoas que estão conectadas por compartilharem internamente diferenças em relação às identidades heterocisnormativas, ao mesmo tempo em que apresentam identidades diversas - gays, lésbicas, bissexuais, travestis, transgêneros etc. Além disso, o grupo LGBTI pode atuar, para fora de sua própria configuração interna, como um 
movimento social, ao apresentar objetivos e interesses, os quais são manifestados politicamente na arena pública de discussão, visando a uma igualdade material de direitos, de liberdades e de participação. Levadas em consideração essas explicações, a implicação dos variados usos do vocábulo grupo se apresenta inteligível em cada ocorrência ao longo do texto.

É nesse ponto que podemos pensar nas dificuldades de se observarem as pessoas LGBTI e as representações de cada letra da sigla dentro do próprio grupo como interessadas nas mesmas conquistas e atravessadas pelas mesmas necessidades. A concorrência interna adquire cores e matizes diversas em relação à posição ocupada na relação sexual, à raça, à classe, às manifestações do comportamento e a maior ou menor proximidade à heterocisnormatividade. Todas essas diferenças dentro do grupo LGBTI promovem, consciente ou dissimuladamente, uma hierarquização de quem pode falar, sobre o que pode falar e como se pode falar. Merece reprodução a nota de rodapé em que Oliveira aponta as razões para tantas mudanças na nomenclatura do grupo e da dança das letras, o que, a se considerarem os propósitos deste ensaio, importa para perceber as assimetrias ainda existentes internamente:

a mudança da sigla está intimamente relacionada à disputa de poder. Trata-se, em grande medida de uma disputa entre grupos de Gays e Lésbicas, pelo reconhecimento e a visibilidade nas políticas sociais. Os Gays reivindicavam a permanência da sigla GLBT por considerar que o movimento nasce como movimento homossexual por agregar apenas homens Gays. Consideram-se pioneiros na criação deste movimento. As Lésbicas retomam a discussão do feminismo, ao justificar a discriminação que ocorre entre homens e mulheres. Travestis e Transexuais uniram seus votos com os das Lésbicas, assim foi aprovado pela maioria à sigla LGBT. Contudo, todo este processo de disputa entre Gays e Lésbicas é traduzida na forma de discursos sobre o significado da identidade masculina e feminino (OLIVEIRA, 2013, p. 31).

A assimetria de poder pode ocorrer tanto no âmbito macro, quanto no micro, ou seja, pode ocorrer tanto entre grupos (intergrupos), quanto dentro de um determinado grupo (intragrupo), uma vez que algumas questões pautadas por determinados sujeitos não possuem o mesmo interesse dos outros membros. Ao pensarmos no grupo LGBTI, podemos perceber que algumas demandas, por exemplo, das sujeitas travestis, das "bichas pretas", das pessoas transgênero não são as mesmas postulações de outras categorias 


\section{R드낸}

dentro do grupo, o que pode apresentar, em algumas circunstâncias, uma desigualdade democrática intragrupo.

Assim, é com foco nessas relações intragrupais que pensamos ser necessária uma reflexão acerca do possível estabelecimento de critérios democráticos deliberativos que informem a construção mais equitativa das pautas e demandas apresentadas para fora do próprio grupo LGBTI. Nesse sentido, a contribuição que pretendemos dar ao debate da teoria da justiça em relação às pessoas LGBTI aborda as diferenças internas nesse grupo pelas lentes de um diálogo entre Nancy Fraser e Rainer Forst.

\section{Participação política interna e as categorias assimétricas de poder}

Alguns teóricos da justiça relacionam as questões de justiça social somente a aspectos distributivos. Nessa perspectiva, teríamos uma igualdade formal, em que essas representações abstratas dos indivíduos dificultam o reconhecimento das desvantagens na vida de alguns sujeitos que estão em desigualdade na relação do poder, o que torna essa abordagem responsável por uma homogeneização social. (MOREIRA, 2017, p. 49).

Diferentemente da padronização interna a grupos ou externa entre eles e pessoas, a teoria crítica realiza uma reflexão sobre a sociedade a partir de teorias da justiça que vão além de uma distribuição igualitária de bens e liberdades. Dentro desse amplo repertório de teorias, podemos realizar conexões entre duas que se nos apresentam aptas a tratar do grupo LGBTI: as teorias da justiça de Nancy Fraser e Rainer Forst, mais especificamente ente o princípio normativo de paridade participativa da primeira autora e o direito fundamental à justificação do segundo autor.

Ressaltamos que nosso objetivo neste trabalho não é realizar uma análise pormenorizada dos modelos de justiça apresentados por Fraser e Forst, tampouco é avaliar se um modelo se apresenta melhor ou mais completo do que o outro. Pretendemos, mais modestamente, produzir uma análise entre pontos convergentes desses dois modelos no sentido de apresentar uma resposta possível acerca da relação e da participação de sujeitos que sofrem determinadas injustiças intragrupo, especificamente dentro do grupo LGBTI. 
Ambos os autores trabalham com perspectivas que vão além do liberalismo e comunitarismo para elaborar suas teorias da justiça ${ }^{5}$. Fraser, como teórica crítica, tem a ambição de conectar os níveis da filosofia moral e da teoria social e análises políticas em uma teoria crítica da sociedade capitalista em "sua totalidade" e acredita que essa crítica logra êxito, tanto teórico quanto prático. A autora utiliza-se de conceitos normativos "que também estão informados por uma compreensão estrutural da sociedade contemporânea que pode diagnosticar as tensões e contextualizar as lutas do presente" (FRASER, 2006, p. 15). Então, ao tentar compreender a situação política global - a partir do contexto póssegunda guerra, em um mundo bipolarizado, com inúmeros conflitos que vão desde o âmbito político, ideológico, social até a corrida espacial, gerando disputas no plano econômico, acentuando as desigualdades materiais entre os países do Norte e Sul global -, Fraser (2001, p. 245-246) elabora sua teoria da justiça, justiça democrática que envolve questões de redistribuição, reconhecimento e representação (ou seja, questões sobre $o$ quê, o quem e o como da justiça), a partir da crítica ao paradigma distributivo do liberalismo igualitário, do termo reconhecimento e da participação dos sujeitados.

De forma semelhante, percebemos que Forst também entende o debate sobre a justiça como um debate sobre o poder, ou melhor, sobre a justificação do poder: "a questão primeira de justiça é a questão do poder" (FORST, 2014, p. 34; 2018, p. 52). E, embora se possa pensar que essa perspectiva se alia apenas a questões distributivas de bens, é possível que se estenda essa afirmação de Forst para as questões de direitos de participação. Afinal, sabe-se "como esses bens surgem no mundo, quem decide sobre sua distribuição e como ela será feita" (FORST, 2014, p. 34; 2018, p. 52) também importa em saber sobre essas mesmas questões quando se trata de incluir ou excluir justificadamente

\footnotetext{
${ }^{5}$ Rainer Forst (2010, p. 09-11) assim se manifesta, ainda que breve e introdutoriamente, sobre liberalismo e comunitarismo: “Comunitarismo' e 'liberalismo' são conceitos genéricos vagos para designar as posições no interior de uma controvérsia que, durante os anos 1980, centrou-se em torno desse problema", qual seja, "as normas que se devem distinguir como justas precisam ser tanto imanentes ao contexto quanto transcendentes a ele. Precisam reivindicar validade para uma comunidade particular e suas autocompreensões e instituições específicas, mas ao mesmo tempo se apresentar como um espelho crítico moral para essas autocompreensões e instituições". Assim, segundo o autor, levando-se em consideração que é "injustificado supor que há homogeneidade em ambos os lados", os comunitaristas criticam os liberais por estes serem "indiferentes ao contexto", ao passo que os liberais criticam os comunitaristas por serem "obcecados pelo contexto", ou seja, na tentativa de resolverem o problema da justiça, os liberais se sustentam sobre princípios deontológicos de prioridade do justo sobre o bom, enquanto os comunitaristas se apoiam sobre princípios derivados do contexto comunitário de prioridade do bom sobre o justo.
}

Vol. 03, N. 10, Abr. - Jun., 2020 - http://periodicoscientificos.ufmt.br/ojs/index.php/rebeh/index 
por meio da linguagem jurídica certos grupos, sobretudo as minorias, ainda que dentro de determinado movimento social.

Forst afirma que, no modelo crítico, o fundamento normativo é o direito moral fundamental à justificação que toda pessoa tem nos esquemas institucionais (FORST, 2012, p. 186). A institucionalização das formas de justificação recíproca e universal faz com que se perceba a democracia como única expressão política adequada ao direito fundamental à justificação e ao respeito mútuo entre as pessoas. O valor dessa normatividade é, portanto, intrínseco à própria democracia. Portanto, "uma estrutura básica justa (justificada) da sociedade contém os direitos que pessoas livres e iguais não podem deixar de conceder e garantir reciprocamente umas às outras e fornecem um modo institucionalizado de justificação recíproca" (FORST, 2012, p. 187).

É possível perceber que Forst tem no conceito de justificação a chave para a produção de uma normatividade justa nas sociedades contemporâneas altamente complexas e plurais. O direito à justificação é extremamente caro ao autor, pois se refere ao direito fundamental de toda pessoa moral e jurídica (no sentido de pessoa do direito) receber razões universalizáveis e recíprocas em um contexto moral de definição da normatividade; direito a que - como sói ocorrer com todo direito - corresponde um dever de justificação das ações moralmente relevantes (ver, por exemplo, FORST, 2002, p. 81; 2012 , p. $21 ; 2013$, p. $8 ; 2014$, p. 34). Conforme ele mesmo assevera, a característica central da democracia consiste

na prática política da argumentação e da fundamentação entre cidadãos livres e iguais, uma prática na qual perspectivas e posições individuais e coletivas estão sujeitas a mudança por meio da deliberação e na qual somente aquelas normas, regras ou decisões que resultam de alguma forma de acordo baseado na razão entre os cidadãos são aceitas como legítimas (FORST, 2012, p. 155).

Em consonância com a característica democrática da justiça, a teoria de Fraser se preocupa, além do "o quê" da justiça, que envolve questões de primeira ordem, com o "quem", que antes era pressuposto como o cidadão nacional. Assim, começa a ser questionado esse “quem”, e é a partir dessa discussão, ou seja, da questão de segunda ordem relacionada ao metanível, ao enquadramento, que Fraser amplia seu escopo da 
justiça6 com uma nova gramática de reivindicação política, que também envolve a relação entre a representação simbólica e a representação como participação política, incluindo, então, a terceira dimensão, o político (FRASER, 2009b, p. 15-16; p. 253).

A autora considera que as outras duas dimensões (tanto o reconhecimento quanto a distribuição) são, também, fatores políticos, mas em natureza (em sentido amplo) e o que ela propõe é um sentido mais estrito de político, "um sentido mais específico, constitutivo, que diz respeito à natureza da jurisdição do Estado e das regras de decisão pelas quais ele estrutura as disputas sociais"7(FRASER, 2009b, p. 19).

A dimensão política, que diz respeito à representação, está pautada em questões de pertencimento e procedimento:

Em um nível, pertinente ao aspecto do estabelecimento das fronteiras do político, a representação é uma questão de pertencimento social. O que está em jogo aqui é a inclusão ou a exclusão da comunidade formada por aqueles legitimados a fazer reivindicações recíprocas de justiça. Em outro nível, pertinente ao aspecto da regra decisória, a representação diz respeito aos procedimentos que estruturam os processos públicos de contestação. Aqui, o que está em questão são os termos nos quais aqueles incluídos na comunidade política expressam suas reivindicações e decidem suas disputas (FRASER, 2009b, p. 19-20, grifos nosso).

A dimensão política é fundamental para colocar as reivindicações a serem debatidas, fornecendo o "palco" de disputas; a representação está incorporada nas reivindicações por redistribuição e por reconhecimento e não há redistribuição nem reconhecimento sem representação (FRASER, 2009b, p. 25). Fraser ressalta que não quer sugerir que a representação é mais importante que as outras duas dimensões, todas se relacionam mutuamente, mas que

[...] a capacidade de influenciar o debate público e os processos autoritativos de tomada de decisão depende não apenas das regras formais de decisão, mas também das relações de poder enraizadas na estrutura econômica e na ordem de status, um fato que é insuficientemente enfatizado na maioria das teorias da democracia deliberativa (FRASER, 2009, p. 25, grifo nosso).

\footnotetext{
${ }^{6}$ A teoria da justiça de Fraser era, a priori, bidimensional, incluía as dimensões da redistribuição e do reconhecimento.

${ }^{7}$ Ver Cap. 2 da Escalas da Justicia - A tradução deste capítulo (Reenquadrando a Justiça em um mundo globalizado - 2009b) foi publicada pela Lua Nova em 2009, São Paulo, 77: 229-236.
}

Vol. 03, N. 10, Abr. - Jun., 2020 - http://periodicoscientificos.ufmt.br/ojs/index.php/rebeh/index 
É neste mesmo sentido que a vai a teoria de Forst (2010, p. 108), ao propor e distinguir quatro conceitos de pessoa e comunidade, formando uma imagem dos diferentes "contextos da justiça", que podem ser resumidos em: normas a serem justificadas de modo recíproco e universal são para cada ser humano, como pessoa moral, normas de ação obrigatória, as quais as pessoas devem justificá-las a outras pessoas diante de um contexto moral. Em contextos político-jurídico, essas normas devem ser traduzidas em direitos humanos e fundamentais, formando o cerne abstrato do conceito de pessoa de direito (proteção da pessoa ética). Forst ainda afirma que os cidadãos são, concomitantemente, autores e destinatários das normas. Tais normas são criadas e transformadas por meio de um discurso argumentativo, um consenso entre cidadãos e é o meio pelo qual as reivindicações por reconhecimento são discutidas e reconhecidas. Desse modo, diz o autor que

Se tomarmos como base o princípio de justificação, a questão política é necessariamente a questão superior da justiça, pois ela é o lugar (se compreendemos a justiça não apenas em um sentido institucional estreito) no qual as práticas culturais, econômicas, políticas e sociais injustas são questionadas e ondem podem ser feitas as modificações no interior dessa esfera (FORST, 2018, p. 199).

Assim, ser, ao mesmo tempo, autor e destinatário das normas de um determinado contexto político-jurídico é atuar no palco deliberativo, no âmbito político, fornecendo reivindicações de justiça e criando a agenda deliberativa. Percebemos que o político é fundamental em ambas teorias, sendo mais um ponto em comum para uma teoria de justiça democrática.

Então, conforme Fraser, se não houver possibilidade de as questões reivindicadas serem expressas politicamente, há frustração na defesa dos interesses de redistribuição e reconhecimento, o que, assegura a autora, desencadeia uma espécie de má representação, havendo, portanto, um ciclo vicioso no sistema de engrenagem de como estas injustiças estão conectadas.

Estando essas três dimensões interligadas, os esforços para superar a injustiça não podem, com algumas exceções, lidar apenas com uma delas. Ao contrário, lutas contra a má distribuição e o falso reconhecimento não serão bemsucedidas a menos que se aliem com lutas contra a má representação - e viceversa. A qual delas se confere ênfase, obviamente, é tanto uma decisão tática quanto estratégica (FRASER, 2009b, p. 25)

Vol. 03, N. 10, Abr. - Jun., 2020 - http://periodicoscientificos.ufmt.br/ojs/index.php/rebeh/index 
Voltando ao nosso problema de pesquisa e com base nos argumentos apresentados, tem-se que os padrões heterocisnormativos de valor permeiam a vida cotidiana e as interações entre os sujeitos, determinando a forma, o modo de agirem e de se comportarem na sociedade. Consequentemente, lésbicas, gays, bissexuais, travestis e transexuais são consideradas representações estereotipadas, são uma forma específica de subordinação de status passíveis de vergonha, hostilidade, agressões, negação de direitos plenos, e quando ocorrem esses danos, ocorrem injustiças de reconhecimento, segundo Fraser (FRASER, 2006, p. 27) e uma negação de direitos como algo reciprocamente não justificável (FORST, 2018, p. 190).

Forst ressalta que o poder de dominar justificadamente, ou seja, de forma não arbitrária, deve se sustentar discursivamente nos critérios de reciprocidade e universalidade. Por isso, é preciso fazer-se uma crítica das relações de justificação, uma vez que essa tem, segundo Forst (2014, p. 7-8; 2018, p. 23-24), cinco tarefas essenciais. A primeira aponta para uma análise crítica das relações sociais, políticas, econômicas e culturais justificadas, isso é, "refere-se a todas aquelas relações e estruturas sociais mais ou menos institucionalizadas que não correspondem ao padrão de justificação recíproca e universal e que são caracterizadas por formas de exclusão, por privilégios e pela dominação arbitrária”. A segunda tarefa implica uma crítica teórica discursiva das falsas justificações de relações sociais assimétricas, "ou seja, aquelas legitimações que não apresentam as relações e estruturas justificadas como relações e estruturas fundamentadas". Por sua vez, a terceira implica, "do ponto de vista reflexivo, a exigência por uma 'estrutura básica da justificação' como primeiro imperativo da justiça”, "como uma moldura para uma práxis discursiva autônoma dos próprios concernidos". A quarta tarefa de uma crítica das relações de justificação “[...] exige uma explicação para o fracasso ou a ausência de estruturas de justificação efetivas em termos políticos e sociais, que seriam propícias para descobrir ou modificar as relações injustificadas". E, finalmente, essa teoria deve ser crítica da própria crítica, ou melhor, deve voltar-se sobre si mesma, pois que ela “não produz nenhuma norma ou ideal 'absolutos', mas sim vincula 
de forma coerente cada pretensão de validade à possibilidade de anuência dos submetidos à norma".

É nesse sentido que Fraser considera que a diferenciação sexual está enraizada na ordem de status, em que "a divisão social entre heterossexuais e homossexuais não se embasa na economia política, uma vez que os homossexuais se distribuem por toda a estrutura de classe da sociedade capitalista, não ocupam uma posição característica na divisão de trabalho e não constituem uma classe explorada.” (FRASER, 2006, p. 27) Entretanto, eles também sofrem graves injustiças econômicas, uma vez que as normas heterossexistas produzem uma categoria que sofrem prejuízos econômicos em razão de seu status subordinado.

A questão da estética de gênero dominante faz com que as travestis e as transsexuais sofram violências específicas que os homossexuais e lésbicas não sofrem quando se adéquam à estética da heterocisnormatividade. "Consequentemente, não só as mulheres, mas todos os grupos de status inferior correm o risco dessa feminilização e, portanto, da depreciação" (FRASER, 2006, p. 29). A autora acredita que a afirmação da diferença identitária barra os esforços para integrar políticas de reconhecimento com políticas distributivas, principalmente para os grupos atingidos, simultaneamente, por mais de uma forma de injustiça. Ressaltamos, neste ponto, uma abordagem interseccional de como todos esses eixos de subordinação não estão radicalmente separados entre si, intersectam-se e influem nos interesses e identidades de todos, ninguém pertence a só uma coletividade e esses eixos exigem, em certa medida, quantidade de redistribuição, reconhecimento e [representação] e a proporção é verificada em cada caso (FRASER, 2006, p. 33).

Assim, ao contrário do modelo de identidade, que apresenta os problemas de sectarização intragrupal, reificação e alguns outros, devido à afirmação da identidade de um grupo, o modelo de status apresentado pela autora (FRASER, 2006, p. 37-39;

\footnotetext{
${ }^{8}$ Feminilização pode ser entendida como a estipulação de atributos simbolicamente construídos como femininos, portanto inferiores, a uma determinada pessoa - como falar baixo, ser pequena, possuir cabelos longos, ser doméstica e domesticada, etc. ou também de atributos ligados à sexualidade e ao poder, como tentar humilhar o outro a partir de uma discriminação sexual, como chamá-lo de "mulherzinha" ou "viado". Ver mais em Bourdieu (2012).
}

Vol. 03, N. 10, Abr. - Jun., 2020 - http://periodicoscientificos.ufmt.br/ojs/index.php/rebeh/index 
FRASER, 2007) possui algumas vantagens: evita essencializar as identidades dos grupos; visa à "elevação" do status de subordinado, portanto, foca na reestruturação social; evita o separatismo, pois promove a interação entre os grupos. Além dessas vantagens, este modelo

[...] é deontológico e não sectário. Incorporando o espírito da "liberdade subjetiva", que é a principal característica da modernidade, ele sustenta que cabe aos indivíduos e grupos definir para si próprios o que conta como boa vida e criar, para si próprios, uma forma de alcançá-la, dentro dos limites que asseguram uma liberdade semelhante para os demais. Assim, o modelo de status não apela para uma concepção da boa vida. Ele apela, ao contrário, para uma concepção da justiça que pode - e deve - ser aceita por aqueles que tenham divergentes concepções da boa vida. O que torna o não reconhecimento moralmente inaceitável, nessa perspectiva, é que isso nega a alguns individuos e grupos a possibilidade de participar, como iguais, com os demais, na interação social (FRASER, 2007, p. 112-113, grifo nosso).

Inserido o reconhecimento dentro do campo da moral universal, Fraser (FRASER, 2006, p. 43) consegue, finalmente, integrar o paradigma distributivo questões objetivas - com o reconhecimento - questões intersubjetivas - e [questões políticas $^{9}$, com a representação] dentro de um único marco normativo da justiça, o princípio de igual valor moral, que é expresso pela paridade participativa, formando uma concepção de justiça democrática.

Segundo essa norma, a justiça exige que os acordos sociais permitam que todos os membros (adultos) da sociedade interajam em pé de igualdade, "o requisito moral é que se garanta aos membros de uma sociedade a possibilidade de uma paridade"

\footnotetext{
${ }^{9}$ No capítulo 2 de Escalas da Justicia (2008) Fraser explica os motivos de incluir esta terceira dimensão. Sua teoria bidimensional da justiça (FRASER, 2009b, p. 11-14) estava amparada no enquadramento do Estado Nacional, na ótica Keynesiano-Westfaliano, em que os atores da justiça não eram contestados, eram os cidadãos nacionais. Mas, com a globalização, muitas questões ultrapassam a fronteira nacional, como, por exemplo, a questão ambiental e feminista, e "as ações das corporações transnacionais, dos especuladores financeiros internacionais e dos grandes investidores institucionais" (FRASER, 2009b, p. 14) - como o Fundo Monetário Internacional (FMI) - estabelecem diretrizes econômicas (trans)nacionais que afetam diretamente e de diferente maneira a vida dos cidadãos e dos que estão além das fronteiras nacionais, fato que torna este enquadramento [Keyseniano-Westfaliano] "um poderoso instrumento de injustiça, que fraciona o espaço político de modo a beneficiar determinado grupo à custa dos pobres e desprezados" (FRASER, 2009b, p. 24). Desta forma, além do "o quê" da justiça, que envolve questões de primeira ordem, o "quem", que antes era pressuposto como o cidadão nacional, começa a ser questionado, e é a partir desta discussão, ou seja, da questão de segunda ordem relacionada ao metanível, ao enquadramento, que Fraser amplia seu escopo da justiça com uma nova gramática de reivindicação política, que também envolve a relação entre a representação simbólica e a representação como participação política, incluindo, então, a terceira dimensão, o político (FRASER, 2009b, p. 15-16; p. 253).
}

Vol. 03, N. 10, Abr. - Jun., 2020 - http://periodicoscientificos.ufmt.br/ojs/index.php/rebeh/index 
(FRASER, 2006, p. 42, nota 39). A teoria se inicia com uma ideia central do liberalismo moderno, "a autonomia e valor moral igual aos seres humanos" (FRASER, 2006, p. 171) e o foco do princípio de paridade participativa não está centrado no plano ético de compartilhamento homogêneo de uma vida boa, mas no plano deontológico, não sectário e substancial que permite o compartilhamento de uma pluralidade de valores razoáveis de uma vida boa e o respeito.

[O princípio] Rechaça, por insuficiente, as ideias formais de igualdade e mantém que, para respeitar a igualdade de autonomia e de valor moral igual entre os demais, é preciso conceder o status de participante de pleno direito na interação social. [...] e a negação do acesso aos pré-requisitos à paridade participativa é fraudar o compromisso professado da sociedade com igualdade de autonomia (FRASER, 2006, p. 172).

Este princípio pode ser interpretado "como a principal expressão da razão pública" (FRASER, 2006, p. 173) e deve ser aplicado de forma trifocal. Serve, como critério geral, para avaliar e julgar se as reivindicações por redistribuição, reconhecimento e representação são justas, busca reduzir as diferenças econômicas, desmantelar os padrões de valores culturais institucionalizados, promovendo uma igualdade de status e conferir expressão política aos sujeitos da justiça.

Uma visão de justiça em termos de paridade participativa representa o desmantelamento de obstáculos institucionalizados que impedem que certas pessoas participem no mesmo nível com outros, como parceiros plenos, em ações sociais. Tais obstáculos podem se apresentar de três formas distintas. $\mathrm{Na}$ primeira, as pessoas podem ser impedidas de participar efetivamente por estruturas econômicas que lhes rejeitam os meios necessários para interagir com outros como iguais; nesse caso, sofrem de injustiça distributiva ou mádistribuição. Na segunda, as pessoas podem ser impedidas de interagir em termos de paridade por meio de hierarquias institucionalizadas de valor cultural que lhes nega a posição necessária; nesse caso, eles sofrem de desigualdade em termos de status ou falso-reconhecimento. na terceira, pessoas podem ser impedidas de praticar uma participação plena por regras estabelecidas, negando-lhes a igualdade em deliberações públicas e na tomada de decisões democráticas; nesse caso, eles sofrem de injustiça política ou márepresentação. Aqui, portanto, temos uma situação em que três formas diferentes de injustiça levam a um resultado comum: em cada caso, alguns atores sociais são impedidos de participar de forma igual com outros em interações sociais. Assim, todas as três formas de injustiça violam um princípio único, o princípio de paridade participativa (FRASER, 2013, p. 752). 
Uma participação igualitária e que também expresse o valor moral igual das pessoas estão presentes nos critérios normativos de reciprocidade e universalidade de Forst. Segundo o autor

[U]um contexto de justiça é sempre um contexto de justificação específico, no qual todas as relações sociais e políticas relevantes, incluindo as relações econômicas, precisam de justificativa recíproca e universal. Por isso, em termos reflexivos, os critérios de reciprocidade e universalidade, de critérios de validade moral convertem-se em critérios de justificação discursiva. Observados sob essa luz, os contextos de justiça são, ao mesmo tempo, contextos de justificação que se apoiam nesses mesmos critérios. Em contra partida, de uma perspectiva da teoria social realista, os contextos de justiça são, em primeiro lugar e em sua maioria, os contextos de injustiça e, na verdade, é somente com a ajuda da análise crítica das diferentes formas de injustiça que se deve construir uma concepção de justiça (FORST, 2018, p. 184-185, itálico no original).

A partir dessas correlações entre as teorias de Forst e Fraser, é possível observar a necessidade de uma análise contextual para um enquadramento de justiça. Em outras palavras, essas duas teorias críticas de uma justiça normativa e reflexiva exigem a realização de uma análise diagnóstico dos contextos/dimensões de injustiça, identificando quais obstáculos impedem a participação, para, então, verificar se as reivindicações realizadas pelos sujeitos são, de fato, justas e se promovem uma igualdade de status, uma paridade participativa, no sentido de ser tratado como um igual dentro do grupo.

\section{Buscando a igualdade internamente para as lutas do movimento}

Após análise do problema à luz dessas conexões realizadas, podemos afirmar que tanto o critério normativo de paridade participativa de Fraser como os critérios normativos de reciprocidade e universalidade de Forst são padrões normativos transformativos que auxiliariam que as sujeitas T pautem e deliberem sobre suas questões de modo justificado, auxiliando em uma não sectarização de interesses e necessidades intragrupais, pois ambos expressam em seu núcleo o valor moral igual que deve ser conferido a cada pessoa.

A primeira razão que se apresenta para corroborar a afirmação de que os princípios normativos das teorias da justiça pensadas por Fraser e Forst contribuem para democratizar as questões de minorias dentro do grupo LGBTI, relaciona-se ao 
entendimento que ambas teorias possuem uma visão do reconhecimento distinta do modelo de identidade. Conforme Fraser, as lutas por reconhecimento travadas em nome de bandeiras identitárias (leia-se modelo de identidade) conferem vigência a uma concepção culturalista do reconhecimento; nesse sentido, o que exige reconhecimento é a identidade cultural específica de um grupo, o que faz com que a política de reconhecimento da identidade, possa apresentar dois problemas (FRASER, 2010, p. 115116). O primeiro é o problema de deslocamento que a política de reconhecimento faz na política de redistribuição, podendo aumentar as desigualdades econômicas; o segundo é o problema de homogeneidade intragrupal, o que refere à possibilidade dos membros do grupo terem que se filiarem a uma identidade coletiva reconhecida, uma espécie de "carta branca". Segundo Fraser (2007, p. 107),

[...] ao negar a heterogeneidade interna, o modelo de identidade obscurece as disputas, dentro dos grupos sociais, por autoridade para representá-los, assim como por poder. Consequentemente, isso encobre o poder das facções dominantes e reforça a dominação interna. Então, em geral, o modelo da identidade aproxima-se muito facilmente de formas repressivas do comunitarismo.

Além disso, esta visão tende a promover uma separação entre grupos (sectarismo intergrupal) podendo promover a reificação cultural "ignorando as interações transculturais, ele trata as culturas como profundamente definidas, separadas e não interativas, como se fosse óbvio onde uma termina e a outra começa. Como resultado, ele tende a promover o separatismo e a enclausurar os grupos em vez de fomentar interações entre eles. (FRASER, 2007, p. 107).

O ponto chave da tese de Fraser é romper com o modelo padrão de reconhecimento, o "modelo da identidade" passando a tratá-lo como "modelo de status". Nesse modelo,

[...] o que exige reconhecimento não é a identidade específica de um grupo, mas a condição dos membros do grupo como parceiros integrais na interação social. O não reconhecimento, consequentemente, não significa depreciação e deformação da identidade de grupo. Ao contrário, ele significa subordinação social no sentido de ser privado de participar como um igual na vida social.[...] significa uma política que visa a superar a subordinação, fazendo do sujeito falsamente reconhecido um membro integral da sociedade, capaz de participar com os outros membros como igual (FRASER, 2007, p. 107-108, grifo nosso). 
Forst (2018, p. 200) também trata do reconhecimento no âmbito de sua teoria da justiça, afirmando que ele é indispensável para lidar com questões de sofrimento e injustiças; mas o reconhecimento para o autor está conectado ao "direito básico de justificação". O "a priori de reconhecimento", nas palavras do autor, deve ser compreendido interpretando o sentido original de reconhecimento kantiano.

[...] interpretação da forma "originária" do reconhecimento moral como "Faktum" de razão justificadora, para usar a famosa e mal-afamada formulação de Kant. Isto é, como o re-conhecimento ao mesmo tempo cognitivo e moral do outro como sujeito de justificação e autoridade a quem eu devo as devidas justificações (nos respectivos contextos). (...) Por isso, não acho que seja unicamente um ato de reconhecimento prático, mas, além disso é um ato de conhecimento:um conhecimento da razão justificadora (FORST, 2018, p. 200201, itálico no original)

Quando Fraser fala em reconhecimento recíproco, ela parte, também, da perspectiva kantiana, de que o respeito é condição da humanidade e deve ser conferido universalmente a todos ${ }^{10}$ Então, o reconhecimento, pautado no modelo de status, confere que os atores sejam reconhecidos, "reconhecimento recíproco", quando os "padrões institucionalizados de valor cultural" (leis, religião, padrões culturais, etc.) os consideram como membros iguais e parceiros na sociedade. Ocorre o contrário, ou seja, há um "mau reconhecimento"/ "reconhecimento errado" ou "subordinação de status", quando estes padrões constituem alguns membros como inferiores, excluídos, marginalizados, invisíveis na sociedade (FRASER, 2007, p. 108). Em outras palavras, a sociedade, a interação social, é regulada por um padrão heterocisnormativo em que normaliza os indivíduos que se sujeitam/agem conforme tais normas e que inferioriza, oprime, segrega, silencia e marginaliza todos os outros que não estão neste padrão, "criando uma classe de pessoas desvalorizadas", subordinadas, e negando-os o direito de participar paritariamente na sociedade (FRASER, 2006, p. 37; FRASER, 2007, p. 109). Consequentemente, a reivindicação de reconhecimento tende a "[...] superar esta subordinação convertendo a parte subordinada em copartícipe pleno da vida social, capaz de interagir com outros em situação de igualdade”. (FRASER, 2006, p. 37).

${ }^{10}$ FRASER, 2006, p. $38-$ Nota $^{\circ} 32$.

Vol. 03, N. 10, Abr. - Jun., 2020 - http://periodicoscientificos.ufmt.br/ojs/index.php/rebeh/index 


\title{
주드태내
}

Neste sentido, é possível perceber que tanto para Fraser quanto para Forst a justiça requer uma condição de igual tratamento, seja a partir da paridade de participação, seja como direito básico à justificação.

\begin{abstract}
Se seguirmos essa concepção, então ajustiça não se refere primordialmente àquilo que alguém tem (ou não tem), mas, em primeiro lugar, a como somos tratados. (...) A justiça visa acabar com a dominação e o exercício arbitrário e injustificado do poder, seja em uma perspectiva política ou social em geral. Portanto, trata-se sobretudo da posição - do status - dos cidadãos como igualdade de direitos na vida política e social, isto é, como pessoas com um direito fundamental à justificação (FORST, 2018, p. 185-186, itálico no original).
\end{abstract}

Não é apenas a partir de um olhar de dentro para fora, ou seja, do grupo para a sociedade que as pessoas LGBTI podem demandar igual respeito, igual consideração, liberdades iguais. Compreendidas as próprias relações internas, o grupo LGBTI pode, observados o direito à justificação e à paridade participativa, iniciar um aprendizado reflexivo e emancipador que organize suas pautas de modo justo a todas as pessoas que compõem a população LGBTI.

\section{Considerações Finais}

Obviamente, importa observar as relações entre o grupo LGBTI e a sociedade, nas disputas pela inclusão política, social e jurídica paritária, igual e livre. Isso, contudo, não impede que se olhe para dentro do movimento LGBTI, a fim de se examinarem as assimetrias de visibilidade e determinação de pautas reivindicatórias.

Os arranjos sociais e as relações de poder foram construídas de modo que estabelecem que alguns sujeitos e algumas demandas sejam classificados como inferiores, o que dificulta ver e "ouvir" o outro, que confere uma assimetria de poder em pautar as necessidades, os interesses dos sujeitos(as) que são assujeitados à determinada(s) injustiça(s). Logo, negar um igual respeito e uma igual participação do sujeito, na sociedade, de modo geral, e dentro do grupo, de modo mais restrito, é violar tanto o princípio normativo da justiça de paridade participativa de Fraser, quanto o critério normativo da justiça de Forst, o direito fundamental à justificação, uma vez que ser impedido de participar como um par, de ser tratado como um igual na sociedade é algo 
injustificável do ponto de vista da razão pública.

Desta forma, o diálogo entre as propostas teóricas de Nancy Fraser e Rainer Forst com foco na democratização das pretensões apresentadas pelos membros do grupo LGBTI se mostrou uma proposta positiva-transformativa, uma vez que o núcleo do princípio/critério(s) normativo(s) de ambos os autores está direcionado a uma noção de tratamento igualitário.

\section{Referências}

BERLANT, Lauren; WARNER, Michael. Sexo en público. In: MÉRIDA JIMÉNEZ, Rafael M. (ed.). Sexualidades Transgresoras: una antología de estudos queer. Traducción de Maria Antònia Oliver-Rotger. Barcelona: Icaria Editorial, 2002. p. 229257.

BOURDIEU, Pierre. A Dominação Masculina. Tradução Maria Helena Kühner. $11^{\mathrm{a}}$ ed. Rio de Janeiro: Bertrand Brasil, 2012.

CARVALHO, Mario; CARRARA, Sérgio. Em direção a um futuro trans?: contribuição para a história do movimento de travestis e transexuais no Brasil. Sex., Salud Soc. (Rio J.), Rio de Janeiro, n. 14, p. 319-351, ago. 2013. Disponível em $<$ http://www.scielo.br/scielo.php?script=sci_arttext\&pid=S1984-

64872013000200015\&lng=en\&nrm=iso>. Acesso em 02 set 2020. http://dx.doi.org/10.1590/S1984-64872013000200015.

FACCHINI, Regina. Histórico da luta de LGBT no Brasil. In: CONSELHO REGIONAL

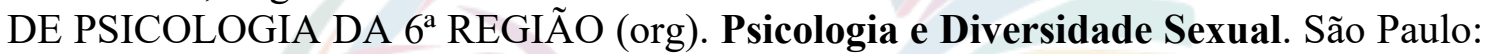
CRPSP, 2011. $\quad$ p. $10-19 . \quad$ Disponível em $<$ http://www.crpsp.org.br/portal/comunicacao/cadernos_tematicos/11/frames/caderno_t ematico_11.pdf $>$. Acessos em: 10 ago 2018.

FONSECA JUNIOR, Arísio Antonio. Reconsiderando a "legislação simbólica" no combate à discriminação de pessoas LGBT+ no âmbito municipal. 2020. $201 \mathrm{f}$. Dissertação (Mestrado em Direito) - Escola de Direito, Turismo e Museologia, Universidade Federal de Ouro Preto, Ouro Preto, 2020.

FORST, Rainer. Contextos da Justiça: filosofia política para além de liberalismo e comunitarismo. Tradução de Denílson Luís Werle. São Paulo: Boitempo, 2010.

FORST, Rainer. Contexts of Justice: political philosophy beyond liberalism and communitarism. Translated by John M. M. Farrell. Los Angeles: University of California Press, 2002.

FORST, Rainer. Justificação e Crítica: perspectivas de uma teoria crítica da política. Tradução de Denílson Luís Werle. São Paulo: Editora Unesp, 2018. 
FORST, Rainer. Justification and Critique: towards a critical theory of politics. Translated by Ciaran Cronin. Cambridge: Polity Press, 2014.

FORST, Rainer. The Right to Justification: elements of a constructivist theory of justice. Translated by Jeffrey Flynn. New York: Columbia University Press, 2012.

FORST, Rainer. Toleration in Conflict: past and present. Translated by Ciaran Cronin. New York: Cambridge University Press, 2013.

FRASER, N. Justiça Anormal. Revista da Faculdade de Direito, Universidade de São Paulo, v. 108, p. 739-768, 22 nov. 2013. Disponível em: $<$ http://www.revistas.usp.br/rfdusp/article/view/68001>. Acesso em: 15 de maio de 2018.

FRASER, Nancy. "Da redistribuição ao reconhecimento? Dilemas da justiça na era póssocialista". In: SOUZA, Jessé (org.). Democracia hoje: novos desafios para a teoria democrática contemporânea. Brasília: EdUnB, 2001.

FRASER, Nancy. In: FRASER, Nancy; HONNETH, Axel. Redistribuição ou reconhecimento? um debate político filosófico. Capítulo 1 e Capítulo 3. Madrid: Ed. Morata S.L, 2006.

FRASER, Nancy. O feminismo, o capitalismo e a astúcia da história. Revista Mediações, Londrina, v. 14, n.2, p. 11-33, Jul/Dez. 2009a. Disponível em $<$ http://www.uel.br/revistas/uel/index.php/mediacoes/article/view/4505>. Acesso em 02 de outubro de 2018.

FRASER, Nancy. Reconhecimento sem ética? Lua Nova, São Paulo, n.70: 101-138, 2007.Disponível em:https://www.scielo.br/scielo.php?pid=S010264452007000100006\&script=sci_abstract\&tlng=pt. Acesso em 16 de setembro de 2017.

FRASER, Nancy. Reenquadrando a Justiça em Um Mundo globalizado. Lua Nova, São Paulo, n.77, p.11-39, 2009b. Disponível em: $<$ http://www.scielo.br/scielo.php?script=sci_arttext\&pid=S0102$64452009000200001 \& \operatorname{lng}=$ en\&nrm=iso $>$. Acesso em: 04 out. 2019.

GOHN, Maria da Glória. 500 anos de lutas sociais no Brasil: movimentos sociais, ONGs e terceiro setor. Revista Mediações, Londrina, v. 5, n. 1, p. 11-40, jan./jun. 2000. Disponível

em: http://www.uel.br/revistas/uel/index.php/mediacoes/article/view/9194/7788. Acesso em: 10 de agosto de 2018.

IRINEU, Bruna Andrade. A política pública LGBT no Brasil (2003-2014): homofobia cordial e homonacionalismo nas tramas da participação social. 2016. 279 f. Tese (Doutorado em Serviço Social) - Programa de Pós-graduação em Serviço Social, Universidade Federal do Rio de Janeiro, Rio de Janeiro, Brasil, 2016.

OLIVEIRA, F. de P. de. O reconhecimento político do movimento LGBT no Brasil: uma análise do processo e das representações de ativistas acerca dos seus efeitos. 2013. 232 f. Tese (Doutorado em Ciências Sociais) - Programa de Pós-Graduação em Ciências Sociais, Centro de Humanidades, Universidade Federal de Campina Grande, Paraíba, Brasil, 2013. 
RODRIGUES, Emely Braga. Que (in)justiça é essa?: A paridade participativa como alternativa ao silenciamento das vozes das mulheres na esfera pública-política. 2020. 130 f. Dissertação (Mestrado em Direito) - Escola de Direito, Turismo e Museologia, Universidade Federal de Ouro Preto, Ouro Preto, 2020.

\title{
CRITICAL THEORY'S CONTRIBUTIONS FOR A REFLECTION ON ASYMMETRIC RELATIONSHIPS WITHIN THE LGBTI GROUP
}

\begin{abstract}
This essay aims to carry out an evaluative exercise of internal relations to the LGBTI group, considered the diagnosis that there are asymmetries within the group of participation and power between people. This circumstance gives some components of the group a preponderance in the establishment of guidelines to be placed outside the movement with the consequent invisibility of minority demands. To try to resolve this situation, we present a dialogue between the theoretical proposals of Nancy Fraser and Rainer Forst as a way to provide members of the LGBTI group with a participatory and deliberative democratic environment in equal presentation of the pretensions.
\end{abstract}

Keywords: Participatory parity. Right to justification. Equality. LGBTI Movement. Critical theory.

Recebido: 15/06/2020

Aceito: 08/09/2020 